\title{
Allowances for care for children with cystic fibrosis
}

\author{
M F Hunter, D P Heaf
}

\section{Attendance allowance}

The attendance allowance was introduced in 1970 to provide financial assistance to those who require frequent or prolonged attention from others as a result of illness or a disabling condition. Assistance may be required because the person requires personal attention to help with bodily functions, mobility around the house, or medication or because the person requires supervision to avoid substantial danger to self or others. ${ }^{1}$ Initially children under the age of 2 years were not eligible to receive the allowance but this ruling was relaxed in April 1990 with the condition that children must need a lot of more help than other children of the same age or sex. Useful information on criteria used to determine eligibility for the allowance has been published by Ennals, ${ }^{2}$ and the Disability Alliance publishes very detailed and helpful advice for applicants. ${ }^{3}$

Attendance allowance is paid at two rates, the higher to those requiring assistance both day and night and the lower to those requiring help either during the day or during the night. The amount of allowance paid has been criticised as being inadequate to provide the level of care needed by recipients since shortly after its introduction. ${ }^{4}$ It is necessary to have required a lot of help for at least six months before attendance allowance can be paid unless the claimant is suffering from an illness likely to result in death within this period. The allowance is not dependent upon the income or savings of the claimant or family. The granting of attendance allowance may allow other benefits, such as housing benefit, to be paid at a higher rate or be one of the qualifying conditions for a carer to claim the invalid care allowance.

\section{Cystic fibrosis}

Cystic fibrosis is a multisystem disorder that places many demands upon sufferers and their families. In the younger child much effort needs to be devoted to physiotherapy and the regular administration of medication, in addition many families find that the efforts needed to ensure adequate dietary intake are time consuming in themselves. The older patient with cystic fibrosis will often need considerable help as well, not only with physiotherapy but also with the administration of intravenous or nebulised drugs. The amount of help needed by older patients is likely to increase as their clinical condition deteriorates.

It would appear that most if not all patients with cystic fibrosis should be eligible to receive attendance allowance. Anecdotal evidence within a regional cystic fibrosis clinic based in
Liverpool suggested that this was not the casemany families reported difficulties in obtaining and keeping the allowance.

Experiences claiming attendance allowance In June 1990 all patients attending the clinic were sent a questionnaire asking whether attendance allowance was currently received and whether the allowance had ever been stopped. They were also asked for information about any appeals that had been made and the period of time between application and receipt of the allowance.

The age of the patient was obtained from clinic records and a measure of disease severity was obtained by reference to their most recent modified Shwachman score. ${ }^{56}$ This score is derived from consideration of the patients clinical condition, lung function measurements, and $x$ ray appearances. Scores for each of the elements are added together to give a total score with a maximum of 100 for a fit person.

Data were analysed using the Mann-Whitney U test.

\section{Results}

Altogether 197 questionnaires were sent out and $118(60 \%)$ were returned; two did not have the patient's name and were excluded from the analysis. Eighty one $(70 \%)$ respondents were currently receiving attendance allowance. Of these $35(43 \%)$ had submitted an appeal before that allowance was granted and $12(15 \%)$ had had their allowance stopped at some point. The mean delay between first applying for and receiving the allowance was $6 \cdot 2$ months (range 1-72).

Thirty five respondents were not receiving the allowance, $20(57 \%)$ of these had applied unsuccessfully and 15 (43\%) had never applied. Twelve $(60 \%)$ of those applying unsuccessfully had appealed against the decision and four of these appeals were still outstanding. Six (30\%) had had attendance allowance stopped and five of these had appealed unsuccessfully against this. Twenty $(17 \%)$ of respondents were receiving mobility allowance and 18 of these were receiving attendance allowance.

The characteristics of the groups of patients receiving or not receiving attendance allowance are shown in the table.

The mean age of the group receiving attendance allowance was significantly less than that of the group refused the allowance $(p<0.05)$ but did not differ from that of the group that had not applied. 
Age and modified Shwachman score for groups receiving and not receiving attendance allowance

\begin{tabular}{lllll}
\hline & $\begin{array}{l}\text { Allowance } \\
\text { received }\end{array}$ & $\begin{array}{l}\text { Allowance } \\
\text { refused }\end{array}$ & $\begin{array}{l}\text { Never } \\
\text { applied }\end{array}$ & p Value \\
\hline No of subjects & 81 & 20 & 15 & \\
Mean age (years) & $4 \cdot 6^{*}$ & $9 \cdot 2^{*}$ & $\mathbf{6 \cdot 8}$ & $*<0 \cdot 05$ \\
Range & $1 \cdot 3-21$ & $1-24$ & $0 \cdot 3-20$ & NS \\
Mean score & 75 & 77 & 80 & (5-100 \\
Range & $25-100$ & $50-95$ & $45-100$ & \\
\hline
\end{tabular}

The modified Shwachman score was not significantly different for the three groups but did show a significant negative correlation with age for the group as a whole $(r=-0.459$, $\mathrm{p}<0.05$ ).

\section{Discussion}

The results of this study appear to confirm the belief held by patients with cystic fibrosis and their families that the granting of attendance allowance is often an arbitrary process. Cystic fibrosis is a progressive disease which worsens with age-as demonstrated in this study by the negative correlation of clinical score with increasing age. Despite this families with younger children are more likely to receive attendance allowance than those with older children. Additionally $15 \%$ of patients receiving the allowance had it stopped after review several years later.

There is no relationship between the clinical condition of the patient and receipt of attendance allowance, indeed there were two patients affected to the degree that they received mobility allowance but did not receive attendance allowance.

In both of these conclusions this study confirmed those performed in Southampton ${ }^{7}$ and Cardiff. ${ }^{8}$

The procedure for assessing claims is likely to be responsible for the inconsistencies revealed in these studies. Claimants fill in an application form with few clinical details and are then visited at home by a doctor employed by the Department of Social Security (DSS) who will not usually have specialist paediatric training. These doctors often appear not to understand cystic fibrosis (one parent reported being asked when her child had caught the condition) and may be deceived by the apparent well being of many older children on initial examination. Many applicants did not feel that the examining doctor understood the time implications of treatment for cystic fibrosis or the fact that the relative good health of some sufferers was a direct result of very hard work on the part of parents.

Altogether $81 \%$ of appeals against refusal of the allowance were successful; the majority of these were supported by a detailed report from the hospital team responsible for the applicant's care. Many parents felt that this report should have formed part of the initial application.

Some of those who had never applied for the allowance had not done so because they were unaware of its existence. This is obviously unacceptable and emphasises that clinicians need to inquire actively and to give advice about social as well as medical issues.

\section{The disability living allowance}

The disability living allowance, which has replaced the attendance and mobility allowances from April 1992 for those aged under 65 has two main components, one for care needs and one for mobility needs. It is possible to claim for and receive one component of the allowance independently of the other. The care component is paid at one of three rates with the higher and middle rates corresponding to the higher and lower rates of the attendance allowance. There is a new lower rate for persons needing some help during the day or needing help to prepare a meal if older than 16 years. The mobility component has two rates, the higher corresponding to the mobility allowance and the lower for persons able to walk but requiring supervision outdoors.

The application procedure for the disability living allowance is very different to that for the attendance allowance. Applicants must fill in two forms that together total 40 pages (some pages need not be completed if the mobility component is not being claimed). ${ }^{9}$ There is space on the form for two statements supporting the application, one from a person knowing the applicant and a second from a doctor or another professional; this space is limited to three column inches.

Once completed the claim form is assessed by a non-medical administrative officer using a DSS manual for guidance. This manual has been written with advice from the Disability Living Allowance Disability Allowance Board and contributions from many organisations representing people with disabilities. Further advice is available from medical staff from the Benefits Agency Medical Services based in the same building. Reports may be requested from professionals involved with the applicant or a medical examination may be requested-it is hoped that this will be needed in only a small proportion of cases (personal communication, Benefits Agency Medical Services).

Appeals against decisions are first dealt with by a different administrator based in the Benefits Agency office in North Fylde. If the applicant is still unhappy they may appeal to the Disability Appeal Tribunal, this is an independent board consisting of a legally qualified chairman, a doctor, and a third member experienced in the needs of disabled people.

\section{A better allowance?}

The introduction of the disability living allowance appears to improve the likelihood of patients with cystic fibrosis receiving financial help. There has been a lot of publicity about the the new allowance which hopefully will increase awareness in both patients and professionals. The application forms give the claimant plenty of opportunity to state how their illness or disability affects them in their daily lives. It is particularly useful that disability and mobility components can be claimed using the same forms. The length and complexity of the forms, however, is likely to discourage many people from applying. It is likely to be important that professionals, particularly doctors, are prepared 
to assist in the completion of this form as the result of the application is largely dependent upon it.

The fact that professionals are invited to contribute to the form goes some way to answering those critics of the system to administering attendance allowance that it did not contact involved doctors until the appeal stage. The space allowed for comment, however, is extremely limited and submission of additional sheets or covering letters is not mentioned on the form. This obviously reduces workload in the short term but may result in unnecessary delays if more detailed reports are requested by the administrator dealing with the claim.

The reduction in number of medical examinations appears likely to meet with the approval of many families in our study and should speed the processing of most claims. Some authors, however, are concerned that the reduction in medical examinations may remove the possibility of applicants having a disability explained on their behalf, ${ }^{10}$ although the experience of many families of children with cystic fibrosis suggests that this medical opinion could also be a hindrance.

The introduction of a third rate to the disability living allowance may reduce the number of applications that are refused but may also reduce the amount of allowance gained by successful applicants. This may lead to a number of appeals as the granting of the middle or lower rate depends on whether the applicant requires 'help' or 'some help' during the day' and the basis upon which this decision is made is not clear.

In summary the introduction of the disability living allowance appears to offer the chance to correct many of the deficiencies concerning the provision of attendance allowance for children with cystic fibrosis. For the first time involved clinicians are invited to contribute early in the application process-it is essential that we use this opportunity to benefit our patients.

1 Department of Social Security. Department of Social Security leaflet DS2. Attendance allowance claim pack. London: HMSO, 1990.

2 Ennals S. Attendance allowance. BMF 1991;302:228-30.

3 Disability Alliance. Attendance allowance guidelines and attendance allowance reviews. London: Disability Alliance, 1983. (Obtainable from 21 Star St, London W2 1QB.)

4 Topliss E. Provision for the disabled. Oxford: Blackwell, 1975: 108-9.

5 Shwachman H, Kilczyki LL. Longterm study of one hundred and five patients with cystic fibrosis. Am $\mathfrak{Y}$ Dis Child 1958; 96:6-15.

6 Taussig LM, Kattwinkel J, Friedewald WT, di Sant Agnese PA. A new prognostic score and clinical evaluation system for cystic fibrosis. $\mathcal{F}$ Pediatr 1973;82:380-90.

7 Peters SA, Rolles CJ. Attendance allowance. BMF 1991; 302:996.

8 Owen G, Maguire S, Ryley H, Goodchild M. Attendance allowance for children with cystic fibrosis. $B M \mathcal{F} 1991$; 302:1210.

9 Department of Social Security. Department of Social Security leaflet $D L A 1$. Disability living allowance claim pack. London: HMSO, 1992

10 Steadman $P$. The new disability living allowance. $B M \mathcal{J}$ $1992 ; 304: 448$

Please see related article of $\mathrm{p} 73$. 